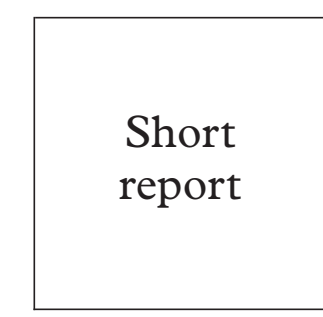

\title{
The prevalence of Chlamydia trachomatis infection in male undergraduates: a postal survey
}

\author{
K E Rogstad, S M Bates, S Partridge, G Kudesia, R Poll, M A Osborne, S Dixon
}

Objectives: To determine the prevalence of Chlamydia trachomatis infection in male undergraduates and to investigate whether prevalence increases with time spent at university. To investigate the feasibility of screening men for $C$ trachomatis by self sampling and posting of urine specimens.

Methods: The study design was a postal survey undertaken by the Department of Genito-Urinary Medicine (GUM) and Student University Health Service (SUHS) in Sheffield. 2607 male undergraduates from the SUHS patient list were invited to participate in the study by providing a first void urine specimen and posting it to the laboratory. The main outcome measure was the detection of $C$ trachomatis infection.

Results: 758 students participated in the study, a response rate of $29.1 \%$. Nine students $(1.2 \%)$ tested positive for $C$ trachomatis. The prevalence of infection in the first, second, and third year of study was $0.7 \%, 1.5 \%$, and $1.6 \%$ of participants respectively. There was no statistically significant difference in prevalence of infection between first and third year students $\left(\chi^{2}\right.$ test, $\left.\mathrm{p}=0.32\right)$. However, students with chlamydia had a higher median age (Mann-Whitney U test, $\mathrm{p}=<0.05$ ). Contact tracing identified four further cases of $C$ trachomatis infection.

Conclusion: Screening for $C$ trachomatis infection by postal survey is feasible. However, the response rate in this study was poor and the estimated sample size was not reached. Therefore, it has not been possible to determine the true prevalence of infection in this population or to accurately assess changes in prevalence with time spent at university.

(Sex Transm Inf 2001;77:111-113)

Keywords: screening; ligase chain reaction; Chlamydia trachomatis; postal survey

Department of

Genito-Urinary

Medicine, Royal

Hallamshire Hospital,

Sheffield, UK

K E Rogstad

$S$ M Bates

R Poll

Public Health

Laboratory Services,

Northern General

Hospital, Sheffield

$S$ Partridge

G Kudesia

Student University

Health Services,

Claremont Place,

Sheffield

M A Osborne

School of Health and

Related Research, University of Sheffield S Dixon

Correspondence to: Dr Sylvia Bates

sylvia.bates@csuh.nhs.uk

Accepted for publication 2 February 2001

\section{Introduction}

The high prevalence of Chlamydia trachomatis in the United Kingdom is partly sustained by the asymptomatic nature of the infection resulting in failure to detect it. Few studies have addressed the issue of screening men for $C$ trachomatis, but those that have report prevalence rates of $4.1-11.3 \% .^{1-3}$ Until recently, invasive procedures have been necessary to provide suitable specimens for $C$ trachomatis testing. The introduction of sensitive nucleic acid amplification techniques (NAA) using first void urine specimens increases patient acceptability and gives the potential for "self sampling."

\section{Subjects and methods}

Male students reaching the age of 19 or 21 during the academic year of the study (September 1998-August 1999) were identified from SUHS patient lists. It was presumed that a majority of these students would be in the first or third year of study. Addresses were available for 1544 students aged 20-21 and 1063 students aged 18-19. Non-responders to the initial request to participate were not followed up.

\section{Methods}

Ethical approval was obtained from South Sheffield research ethics committee.

Students were sent an explanatory letter, information sheet, and brief demographic questionnaire together with an appropriately packaged specimen bottle conforming with the
International Air Transport Authority 650 Regulations for Transport of Pathological Specimens. The packages were discreet and small enough to be posted through a standard letterbox $(3.5 \times 5.5 \times 12 \mathrm{~cm})$. All were issued with first class return postage and addressed directly to the Public Health Laboratory.

Students were asked to fill the bottle with first void urine and return it by post on the same day (avoiding the weekend to reduce specimen time at ambient temperature). Confidentiality was maintained by using numbered specimen bottles.

Specimens were tested by LCR using the Abbott LCX system (Abbott Laboratories Diagnostics Division, IL, USA) in pools of five. Pool size was determined as follows:

Proportion of positive pools $=1-(1-p)^{n}$

$\mathrm{p}=$ expected prevalence $-1-4 \%, \mathrm{p}=0.01$ to 0.04

$\mathrm{n}=$ number of samples in pool.

Urine specimens were refrigerated on receipt in the laboratory and frozen $\left(-20^{\circ} \mathrm{C}\right)$ within 48 hours. Specimens were thawed and thoroughly mixed before testing. One $\mathrm{ml}$ of each specimen was extracted for LCR and $20 \mu \mathrm{l}$ aliquots of the extract from each specimen were combined and tested. When a pool gave a positive result, each specimen was tested individually. In each split pool only one constituent tested positive. These specimens were designated confirmed positives having given a positive result by LCR on two occasions. ${ }^{4}$ 
Participants were informed of their results by post. Those with chlamydia were invited to attend the GUM clinic where a further urine specimen was tested by EIA (Dako IDEIA PCE) and DIF (Syva Micro Trak Chlamydia trachomatis Direct Specimen Kit) to confirm infection. Subsequent management was in accordance with standard clinic protocol.

STATISTICAL METHODS

Sample size was determined assuming a $1 \%$ prevalence in first year students, rising to $4 \%$ in the third year. Calculations suggested 575 participants would be needed from each year to have a $90 \%$ power of detecting a difference at the $5 \%$ significance level. Results were analysed by $\chi^{2}$ and Mann-Whitney U tests using a statistical package (sPss).

\section{Results}

RESPONSE RATE

A total of 758 students provided urine specimens, a response rate of $29.1 \%$.

\section{RECEIPT OF SPECIMENS}

One specimen was unsuitable for analysis; $80.9 \%$ (533) of specimens where time of collection was provided were received within one calendar day of collection (table 1).

\section{PREVALENCE}

Nine students tested positive for $C$ trachomatis $(1.2 \%)$. The prevalence of infection was $0.7 \%$, $1.5 \%$, and $1.6 \%$ in first, second, and third year students respectively (table 2 ). There was no statistically significant difference between first and third year students $\left(\chi^{2}\right.$ test, $\left.\mathrm{p}=0.32\right)$. However, the median age of infected students was higher than uninfected students (MannWhitney $\mathrm{U}$ test, $\mathrm{p}=<0.05$ ).

CONTACT TRACING

The nine males with $C$ trachomatis infection named 16 contacts. Four tested positive for $C$ trachomatis, and each was linked to a different index case. Of the remainder, six contacts were confirmed to have been treated and six were untraceable owing to lack of information. Overall, $10(62.5 \%)$ of contacts received treatment.

Table 1 Time from collection of specimen to receipt in laboratory

\begin{tabular}{lcll}
\hline & $\begin{array}{l}\text { Number of samples } \\
\text { received }(n=758)\end{array}$ & $\begin{array}{l}\text { Percentage of samples } \\
\text { received }(n=758)\end{array}$ & $\begin{array}{l}\text { Percentage of samples } \\
\text { for C trach positive }\end{array}$ \\
\hline Same day & 5 & $0.7 \%$ & 0 \\
One day & 528 & $69.6 \%$ & 55.6 \\
Two days & 67 & $8.8 \%$ & 11.1 \\
Three days & 23 & $3.0 \%$ & 11.1 \\
Four days & 13 & $1.7 \%$ & 0 \\
More than 4 days & 23 & $3.0 \%$ & 0 \\
Information not specified & 99 & $13.2 \%$ & 22.2 \\
\hline
\end{tabular}

Table 2 Prevalence of Chlamydia trachomatis infection by year of study

\begin{tabular}{llll}
\hline Year of study & $\begin{array}{l}\text { Number of students } \\
\text { participating in study }\end{array}$ & $\begin{array}{l}\text { Number of students } \\
\text { infection }\end{array}$ & $\begin{array}{l}\text { Prevalence of C } \\
\text { trachomatis infection }\end{array}$ \\
\hline First year & 284 & 2 & $0.7 \%$ \\
Second year & 133 & 2 & $1.5 \%$ \\
Third year & 316 & 5 & $1.6 \%$ \\
Fourth or subsequent year & 7 & 0 & $0 \%$ \\
Not specified & 18 & 0 & $0 \%$ \\
\hline
\end{tabular}

\section{Discussion}

The prevalence of $C$ trachomatis infection detected in this study is lower than that previously reported in asymptomatic men. ${ }^{23}$ However, our response rate was low and the results may not reflect the true prevalence of infection among students. It is possible that students at most risk of $C$ trachomatis infection may have decided not to participate, so introducing a sample bias. Alternatively, some participants may not have been sexually active or may have been practising safer sex.

Postal surveys have been used successfully by other investigators to screen for $C$ trachoma$t i s .{ }^{5}$ Unfortunately, low response rates are frequently reported, resulting in failure of screening programmes. This can occur as a result of unwillingness to participate due to fear, stigma or lack of motivation. Inadequate population registers will further reduce response rates. ${ }^{7}$ Students are a highly mobile population and do not frequently visit their general practitioner, so registered addresses may be incorrect. Some investigators have gone to great lengths to encourage participation in similar studies, but this approach is unlikely to be practical in a non-study postal screening service. ${ }^{5}$

Six of the male students with $C$ trachomatis $(66.7 \%)$ were asymptomatic when they attended clinic and four had only one sexual partner in the past year. It is unlikely that these infections would have been diagnosed without screening. Screening also promotes increased awareness of $C$ trachomatis.

It was not possible to maintain a strict cold chain with urine samples before LCR testing as recommended by the manufacturers. However, some studies have shown that this is not necessary. ${ }^{4}$ Pooling samples could theoretically introduce the risk of an inhibitor from one sample affecting an entire pool, but this method has been shown to be acceptable for screening and the inhibitory effect is reduced by dilution. ${ }^{8}$

The cost of the survey and tests to the NHS was $£ 12770$, which produces a cost per index case detected of $£ 1419$. Once clinic attendances, tests, and treatment are included this rises to $£ 1508$. These figures are likely to underestimate the cost effectiveness as no account has been taken of subsequent contact tracing or cost savings in future years due to reduced medical complications associated with $C$ trachomatis infection. Previous studies indicate that cost reductions are possible with contact tracing ${ }^{10}$ and by avoiding future disease. ${ }^{11}$ However, given the low prevalence of $C$ trachomatis in this population it is unlikely that they would reduce the cost effectiveness of this screening intervention significantly. Costs incurred in future postal surveys will be even higher if IATA 602 specifications become necessary for the postage of specimens as the packaging is expensive (currently over $£ 5$ per package) and too large for a standard letter box, necessitating collection or the use of a courier service. ${ }^{12}$ 


\section{Conclusion}

In this study we have demonstrated that screening for $C$ trachomatis infection by self sampling and posting of urine specimens is possible. However, there are several practical difficulties associated with postal screening, particularly low response rates, and this approach has not been demonstrated to be cost effective in this low risk population.

Conflict of interest: None.

We thank Trimedica, Trinity Pharmaceuticals Ltd, for financial assistance towards administrative costs of the study.

Contributors: KR, study design and review of manuscript; SB, Contributors: KR, study design and review of manuscript; SB,
study management, data collection and preparation of manustudy management, data collection and preparation of manu-
script; SP, laboratory analysis of specimens, data collection and script; SP, laboratory analysis of specimens, data collection and
preparation of manuscript; GK, setting up laboratory protocol preparation of manuscript; GK, setting up laboratory protocol for testing of specimens, coordination of specimens and review of manuscript; RP, contact tracing, data collection and prepara-
tion of manuscript; $\mathrm{MO}$, provision of patient database, protocol tion of manuscript; $\mathrm{MO}$, provision of patient database, protocol tion and preparation of manuscript.

1 Stary A, Tomazic-Allen S, Choueiri B, et al. Comparison of DNA amplification methods for the detection of Chlamydia trachomatis in first-void urine from asymptomatic military recruits. Sex Transm Dis 1996;23:97-102.
2 Shafer MA, Schachter J, Moncada J, et al. Evaluation of Shafer MA, Schachter J, Moncada J, et al. Evaluation of
urine-based screening strategies to detect Chlamydia urine-based screening strategies to detect Chlamydia males. $\mathcal{F} A M A$ 1993;270:2065-70.

3 Podgore JK, Holmes KK, Alexander ER. Asymptomatic urethral infections due to Chlamydia trachomatis in male US military personnel. F Infect Dis 1982;146:828.

4 McCartney RA, Howe I, Bell F, et al. The routine use of the ligase chain reaction (LCR) in the laboratory diagnosis of genital Chlamydia trachomatis infections: a 12 month study. SCIEH Weekly Report 1998;32:201-2.

5 Macleod J, Rowsell R, Horner P, et al. Postal urine specimens: are they a feasible method for genital chlamydia infection screening? Br f Gen Pract 1999;49:455-8.

6 Ostergaard L, Moller JK, Andersen B, et al. Diagnosis of urogenital Chlamydia trachomatis infection in women based on mailed samples obtained at home: multipractice comparative study. BMF 1996;313:1186-9.

7 Bowling A, Jacobs B. Screening: the inadequacy of population registers. BMf 1989;298:545-6.

8 Notomi T, Ikeda Y, Okadome A, et al. The inhibitory effect of phosphate on the ligase chain reaction used for detecting Chlamydia trachomatis. F Clin Path 1998;51:306-8.

9 Kacena KA, Quinn SB, Howell MR, et al. Pooling urine samples for ligase chain reaction screening for genital Chlamydia trachomatis infection in asymptomatic women. f Clin Micro 1998;36:481-5.

10 Howell MR, Kassler W J, Haddix A. Partner notification to prevent pelvic inflammatory disease in women. Cost effectiveness of two strategies. Sex Transm Dis 1997;24:287-92.

11 Genc M, Mahrd PM. A cost-effectiveness analysis of screening and treatment for Chlamydia trachomatis infection in asymptomatic women. Ann Intern Med 1996;124:1-7.

12 Bates SM, Rogstad KE. Postal research: too many problems? Sex Transm Inf 2000;76:332-4. 